\title{
Relação escola-família e o papel do coordenador pedagógico: estado do conhecimento
}

\author{
Alice Felisberto da Silva* \\ Maria Ângela Bariani de Arruda Fachini**
}

\begin{abstract}
Resumo
No presente artigo, busca-se identificar como a produção acadêmica tem abordado o papel do coordenador pedagógico na relação escola-família. Para tanto, realizou-se um levantamento do estado do conhecimento sobre o referido objeto nas principais bases de dados acadêmicas brasileiras. O estudo revelou uma escassez de trabalhos com a referida temática. Nos trabalhos analisados, o papel do coordenador pedagógico aparece como multifacetado: ora como um formador dos professores, ora como um mediador de conflitos, ora como um ouvinte/orientador das famílias. Enfatiza-se a importância desse agente no planejamento e implementação da proposta pedagógica da escola e como um representante da instituição, que apresenta esta à família. São depositadas, ainda, sobre o coordenador, expectativas em relação ao auxílio na elaboração das aulas, organização das reuniões e demais atividades que integrem a família à escola, além da composição dos dados estatísticos sobre o rendimento dos alunos.
\end{abstract}

Palavras-chave: Escola; Família; Coordenador Pedagógico.

\section{School-family relationship and the role of pedagogical coordinator: state of knowledge}

\begin{abstract}
In this article, we seek to identify how the academic research has addressed the role of the pedagogical coordinator in the school-family relationship. To this end, we performed a search of the state of knowledge about this object in the Brazilian academic data bases. The research revealed a lack of studies with this theme. In the analyzed studies, the role of pedagogical coordinator appears as multifaceted: sometimes as a trainer of teachers, sometimes as a conflict mediator, either as a families' listener/advisor. We point to the importance of this agent in the planning and implementation of the school pedagogical proposal and as a representative of the institution, which presents this to the families. Are also placed on the coordinator, expectations for aid in the preparation of lessons, organization of meetings and other activities that integrate family to school, besides the composition of statistical data on student performance.
\end{abstract}

Keywords: School; Family; Pedagogical Coordinator.

\section{Introdução}

No presente artigo, pretende-se identificar como a produção acadêmica tem abordado o papel do coordenador pedagógico na relação entre a instituição escolar e a instituição familiar, ou seja, que importância tem sido atribuída a esse profissional como um mediador entre os anseios da escola e os da família. Para tanto, os objetivos específicos são: promover um levantamento do estado do conhecimento sobre o referido objeto nas bases de dados da Biblioteca Digital Brasileira de Teses e Dissertações (BDTD) e da Scientific Electronic Library Online (Scielo); identificar as teorias e metodologias empregadas pelos pesquisadores nesses estudos; identificar os grupos sociais que essas investigações contemplam; e entender a importância atribuída ao coordenador pedagógico como mediador na relação escolafamília.

A relevância dessa proposta refere-se ao fato de essa questão estar em pauta nos dias atuais, tanto dentro quanto fora da academia. No âmbito acadêmico, estudos e pesquisas realizados por nós ${ }^{1}$

*Endereço eletrônico: alicefsonline@ gmail.com

**Endereço eletrônico: angelafachini @ terra.com.br têm revelado a pertinência de trabalhos que se debrucem sobre a relação entre a escola e a família. O referencial utilizado em nossos estudos é Bourdieu e seus interlocutores. Essa perspectiva teórica evidencia a importância das ações parentais nas trajetórias escolares, o que vem ao encontro das situações com as quais nos deparamos cotidianamente em nosso exercício profissional.

Ao se realizar um estado do conhecimento sobre essa temática, pretende-se evidenciar possíveis lacunas a serem exploradas em estudos posteriores, além de contribuir para que os próprios coordenadores, uma vez tendo contato com este trabalho, pensem sobre o seu papel e busquem práticas que favoreçam a relação escola-família.

No presente trabalho, busca-se entender como o papel do coordenador pedagógico tem sido abordado em trabalhos que enfocam a relação escola-família. Sendo assim, a problematização que fomenta a discussão é a seguinte: 1) Qual a incidência de investigações que tratam da relação escola-família, em especial no que se refere à função desempenhada pelo coordenador pedagógico? 2) Quais as abordagens teóricas e 
metodologias empregadas nesses estudos? 3) Quais grupos sociais têm sido enfocados? 4) Qual a relevância atribuída ao coordenador pedagógico nesse processo?

Para contemplar os objetivos e problematização aqui levantados, o artigo está organizado da seguinte forma: no primeiro tópico, intitulado "Estado do conhecimento acerca da relação escola-família e o papel do coordenador pedagógico", apresenta-se um levantamento das produções acadêmicas sobre o objeto; no segundo tópico, intitulado "Da relevância social e acadêmica do objeto de estudo", busca-se evidenciar, a partir do levantamento realizado, possíveis lacunas a serem exploradas em estudos posteriores em relação ao objeto aqui estudado e sua relevância social e acadêmica; por fim, nas considerações finais, são sintetizadas as discussões realizadas ao longo do texto.

\section{Estado do conhecimento acerca da relação escola-família e o papel do Coordenador Pedagógico}

Neste tópico, serão apresentadas as produções que foram levantadas nas bases de dados consultadas. A busca foi realizada nos sites da Biblioteca Digital Brasileira de Teses e Dissertações (BDTD) e Scientific Electronic Library Online (Scielo). Selecionaram-se estas por comportarem um universo significativo das produções acadêmicas brasileiras - respectivamente, as dissertações e teses e os artigos científicos. Não foi realizado recorte temporal para a busca dos trabalhos.

Em relação à BDTD, a busca por dissertações e teses com as palavras-chave ${ }^{2}$ relacionadas ao objeto retornou um total de 8 trabalhos, conforme quadro abaixo:

Quadro 1: Dissertações e teses da BDTD que abordam a relação escola-família e o papel do coordenador pedagógico

\begin{tabular}{|c|c|c|c|c|}
\hline Título & Ano & Instituição & Curso & Autor \\
\hline $\begin{array}{c}\text { Família e escola na educação infantil: um estudo } \\
\text { sobre reuniōes de pais }\end{array}$ & 2005 & USP & $\begin{array}{c}\text { Mestrado em } \\
\text { Psicologia }\end{array}$ & $\begin{array}{c}\text { Heloisa Helena } \\
\text { Genovese de Oliveira } \\
\text { Garcia }\end{array}$ \\
\hline $\begin{array}{c}\text { A relação escola e família no Ensino Fundamental } \\
\text { da rede privada na perspectiva do Coordenador } \\
\text { Pedagógico }\end{array}$ & 2006 & PUC-SP & $\begin{array}{c}\text { Mestrado em } \\
\text { Educação }\end{array}$ & Jussara Fernandes \\
\hline $\begin{array}{c}\text { Família na escola: olhando fotografias, lendo } \\
\text { textos culturais }\end{array}$ & 2007 & Unisinos & $\begin{array}{c}\text { Mestrado em } \\
\text { Educação }\end{array}$ & Mara Marisa da Silva \\
\hline $\begin{array}{c}\text { Contribuições de famílias para o rendimento } \\
\text { escolar de alunos de 1 a 4 séries do ensino } \\
\text { fundamental: olhares das responsáveis e das } \\
\text { professoras }\end{array}$ & 2008 & UCSAL & $\begin{array}{c}\text { Mestrado em } \\
\text { Sociedia na } \\
\text { Contemporânea }\end{array}$ & $\begin{array}{c}\text { Rita de Cássia Araújo } \\
\text { Freitas de Moraes }\end{array}$ \\
\hline $\begin{array}{c}\text { É possível promover o sucesso escolar? : um } \\
\text { estudo a partir do pensamento das educadoras das } \\
\text { séries iniciais }\end{array}$ & 2009 & USP & $\begin{array}{c}\text { Mestrado em } \\
\text { Educação }\end{array}$ & $\begin{array}{c}\text { Sandra Giovina Ponzio } \\
\text { Ferreira }\end{array}$ \\
\hline $\begin{array}{c}\text { A relação entre a família e a creche pública no } \\
\text { cuidado e na educação das crianças }\end{array}$ & 2011 & UNICAMP & $\begin{array}{c}\text { Doutorado em } \\
\text { Educação }\end{array}$ & $\begin{array}{c}\text { Maria das Graças } \\
\text { Oliveira }\end{array}$ \\
\hline $\begin{array}{c}\text { A responsabilidade social no mercado escolar: } \\
\text { uma análise sociológica das demandas parentais } \\
\text { em suas relações com a oferta educativa }\end{array}$ & 2012 & UFMG & $\begin{array}{c}\text { Doutorado em } \\
\text { Educação }\end{array}$ & $\begin{array}{c}\text { Stefania de Resende } \\
\text { Negri }\end{array}$ \\
\hline $\begin{array}{c}\text { A relação professor-escola-família na educação da } \\
\text { criança de 4 a 6 anos: estudo de caso em duas } \\
\text { instituições de ensino da cidade de Londrina }\end{array}$ & 2012 & USP & $\begin{array}{c}\text { Doutorado em } \\
\text { Educação }\end{array}$ & Gilmara Lupion \\
Moreno
\end{tabular}

\section{Fonte: BDTD, 2014. Organização: Silva, 2014.}

Na Scielo, por sua vez, não foi encontrado trabalho algum referente à temática. Foram realizadas diversas combinações de palavras-chave, porém não houve resultados. Inclusive, ao se colocar somente a palavra-chave "coordenador pedagógico" e "coordenação pedagógica", dos poucos resultados encontrados $(4$ e 10 , respectivamente), nenhum se referia à relação escola-família.

Essa escassez de trabalhos é um dado preocupante, principalmente quando se considera que se trata de um objeto que precisa ser explorado. Nos últimos anos, é crescente a discussão a respeito da relação entre escolas e famílias. Isso não se 
restringe ao campo acadêmico, pois as mídias e a sociedade em geral têm destacado a importância de uma parceria entre essas duas instituições sociais, no sentido de favorecer a aprendizagem dos alunos. É senso comum que a presença da família, o acompanhamento constante, por parte dos responsáveis, da vida escolar de seus filhos, tende a favorecer essas trajetórias. A academia, por sua vez, tem se debruçado, por meio de estudos com enfoque sociológico, sobre os processos que envolvem essa relação.

Há hoje um consenso, entre os pesquisadores, quanto a uma intensificação e um estreitamento dos laços que ligam essas duas importantes instâncias de socialização das sociedades contemporâneas, com os contatos formais e informais entre elas se diversificando e se multiplicando de modo nunca antes visto. (DAYRELL et. al, 2012, p. 12).

Os autores destacam, ainda, que as mudanças ocorridas nessas duas instituições, com a redefinição de seus respectivos papéis, além dos incentivos governamentais à participação das famílias na gestão dos estabelecimentos de ensino, têm influenciado as pesquisas sobre o tema, as quais têm se voltado às relações micro, dentro dos grupos sociais e famílias, visando a descortinar suas estratégias, as ações empregadas na escolarização de seus filhos. "Estudos sobre as relações entre a escola e a família têm permitido, entre outras questões, dar visibilidade às práticas de escolarização e ao valor social da educação institucionalizada em diferentes segmentos sociais." (ZAGO, 2008, p. 23).

Sendo assim, diante de um cenário em que a relação família-escola (ou, no caso aqui enfocado, escola-família) tem sido enfatizada nas pesquisas em educação ${ }^{3}$, buscando entender como essas duas instituições têm empregado ações combinadas no sentido de favorecer as trajetórias escolares, surpreende que poucos estudos contemplem o papel do coordenador pedagógico nesse processo, principalmente ao se considerar que este é um agente mediador que busca conciliar a organização escolar e as demandas das famílias.

Outro aspecto a ser observado são as áreas de concentração. Predominantemente, a área das pesquisas é a de Educação, havendo um equilíbrio no que se refere ao nível desses cursos (dos 6 trabalhos, 3 são de doutorados e 3 de mestrados). Observando essa escassez, levanta-se a hipótese de que, se os cursos de pós-graduação lato sensu disponibilizassem os trabalhos de seus egressos, talvez essa produção seria maior, pois os profissionais que buscam esses cursos direcionam seu objeto ao seu campo de atuação. É preocupante que, mesmo com os avanços da tecnologia, as instituições ainda não tenham desenvolvido mecanismos de divulgar os trabalhos de conclusão de curso (TCCs) das graduações e especializações. A única possibilidade para se ter acesso a essa produções é por meio de eventos e periódicos, porém o que se observa é que o maior público atingido por estes são os pesquisadores que atuam nas universidades (sejam bolsistas de iniciação científica, mestrandos, doutorandos e professores universitários, que são incentivados - e muitas vezes até mesmo pressionados - a produzir), e há pouca participação dos profissionais que atuam nas escolas e/ou graduandos não-bolsistas.

Em relação às produções por região, observa-se uma ausência de trabalhos nas regiões Norte e Centro-Oeste. São predominantes as produções na região Sudeste. Esse dado também foi observado em outro estudo realizado - cujo enfoque é a produção do sucesso escolar nas camadas populares $^{4}-$, o qual identificou um maior volume de trabalhos nas regiões Sudeste e Sul. Levantou-se como hipótese que isso se deve ao fato de essas regiões possuírem um maior número de programas de pós-graduação ${ }^{5}$, concentrando $70 \%$ do total de cursos de mestrado e doutorado. As regiões Norte e Centro-Oeste, juntas, concentram somente $12 \%$ do total de cursos, menos do que a região Nordeste, que possui $18 \%$, segundo informações obtidas no portal da CAPES.

No que se refere ao objeto, prevalecem os trabalhos cujo enfoque é a presença da família na escola. No entanto, chama a atenção o fato de que, embora a busca seja por trabalhos que abordem sobre o coordenador pedagógico, nenhuma das produções levantadas dá destaque a esse aspecto. Somente as dissertações de Fernandes (2006) e Ferreira (2009) dão uma ênfase maior a esse profissional. Posteriormente, essa questão será esmiuçada, trazendo dos trabalhos levantados como esse agente tem sido caracterizado nos referidos estudos.

Uma vez feita essa exposição quantitativa das produções levantadas, passa-se a uma leitura mais atenta dos trabalhos, apresentando suas características e, especificamente a respeito do objeto estudado neste artigo, como o coordenador pedagógico é enfatizado - ou não - pelos pesquisadores.

O primeiro trabalho é a dissertação de mestrado (em Psicologia) de Garcia (2005), intitulada "Família e escola na educação infantil: um estudo sobre reuniões de pais". A autora 
promoveu um estudo em duas escolas municipais de educação infantil paulistanas, buscando analisar como se constituem as relações das escolas com os familiares dos alunos durante as reuniões de pais. Tomou-se como referencial o construtivismo piagetiano e como metodologia observações de reuniões e entrevistas. Observou-se uma secundarização das discussões sobre os aspectos pedagógicos e um caráter moralizador, por parte das instituições escolares pesquisadas, em relação à educação desenvolvida pelas famílias, além de discussões políticas e institucionais pouco relacionadas ao trabalho desenvolvido com as crianças. Outra crítica trazida pela autora é a postura da escola frente à família, pouco receptiva às contribuições desta definida como detentora do saber.

Em relação ao papel desempenhado pelo coordenador pedagógico nas instituições pesquisadas, a autora caracteriza-o da seguinte forma: "[...] supervisionam o trabalho diário do professor incluindo as reuniões [...]." (GARCIA, 2005 , p. 84). A autora ainda destaca a relevância do papel desse profissional a partir do que pode analisar em sua pesquisa:

Entra em cena aqui, uma função institucional que ocupa posição fundamental frente ao tema da nossa pesquisa: o coordenador pedagógico. Numa das escolas, de maneira explícita, várias professoras atribuíram ao contato com uma determinada coordenadora pedagógica as suas aprendizagens sobre reuniões de pais. Destacaram sua postura de valorização desses espaços e a implantação de uma proposta considerada avançada de inclusão ativa dos pais na reunião. Foi com ela que aprenderam a realizar as oficinas, planejando situações vivenciais para os pais, sempre relacionadas aos projetos pedagógicos. A importância dessa profissional torna-se ainda maior porque, como informaram-nos todas as entrevistadas, na formação inicial de professor, seja no magistério, seja em nível superior, não existe espaço para esse tema. $E$ tanto é importante o trabalho da coordenação que, com a mudança simultânea de diretora e coordenadora pedagógica nessa EMEI, ocorreram reflexos nas reuniões, sentidos $e$ mencionados inclusive nas entrevistas de vários pais. (GARCIA, 2005, p. 182).

Observa-se, portanto, que, ainda que a pesquisadora caracterize o coordenador como um "supervisor", os dados de sua pesquisa colocam esse profissional como um formador e articulador entre pais e professores. A dinâmica das reuniões tinha influência direta do perfil da coordenação pedagógica, pois os docentes dependiam das orientações desta para dar os encaminhamentos.

$\mathrm{O}$ segundo trabalho analisado trata-se da dissertação de mestrado (em Educação) de Fernandes (2006), intitulada "A relação escola e família no Ensino Fundamental da rede privada na perspectiva do Coordenador Pedagógico". Ele apresenta como objetivo conhecer e compreender como ocorre a relação entre escola e família em um grupo de escolas privadas, na perspectiva do coordenador pedagógico. A autora pesquisou cinco escolas e realizou entrevistas semiestruturadas com os coordenadores dessas instituições, buscando entender as estratégias das escolas em sua relação com as famílias de alunos de $1^{\mathrm{a}}$ a $4^{\mathrm{a}}$ série do ensino fundamental. Seu estudo revelou que a maioria dos pais estabelece uma parceria com as escolas e, nos casos em que as instituições enfrentam uma ausência da família, têm buscado atividades que ampliem essa participação.

Em relação ao papel do coordenador pedagógico, a autora ressalta que há a necessidade deste ouvir o professor, por exemplo, na definição das pautas das reuniões, promovendo um trabalho de troca, e não soluções prontas. "Segundo Althuon et al (1996), o processo de preparação e o resultado de uma boa reunião de pais está no próprio professor e não no coordenador e diretor da escola." (FERNANDES, 2006, p. 42). Embora, nessa pesquisa, os coordenadores pedagógicos recebam um destaque, justamente por serem os sujeitos entrevistados, a sua função é pouco abordada, ficando o enfoque somente sobre a participação das famílias.

A dissertação de mestrado (em Educação) de Silva (2007), intitulada "Família na escola: olhando fotografias, lendo textos culturais", traz uma abordagem e metodologia diferenciadas do tema, inclusive devido ao referencial adotado pela autora: o foucaultiano. Foram analisadas fotografias de momentos de presença da família na escola, nas diferentes atividades promovidas (como palestras, oficinas, passeios, festas). Não foi possível o acesso ao trabalho na íntegra, porém no resumo o coordenador pedagógico é mencionado como um dos sujeitos entrevistados.

A dissertação de mestrado (em Família na Sociedade Contemporânea) de Moraes (2008), intitulada "Contribuições de famílias para o rendimento escolar de alunos de 1 a 4 séries do ensino fundamental: olhares das responsáveis e das 
professoras", apresenta como objetivo geral investigar a participação das famílias no favorecimento do rendimento escolar de alunos nas referidas séries, em uma escola municipal urbana do interior da Bahia, segundo os olhares das responsáveis e das professoras das crianças. A pesquisadora entrevistou 18 responsáveis pelas crianças de melhor rendimento e 18 de crianças com baixo rendimento, além das professoras das turmas pesquisadas e do coordenador pedagógico, e traçou um perfil das famílias das crianças de maior e menor rendimento escolar, observando que aquelas cujos filhos tinham um bom desempenho eram, em sua maioria, empregadas, com uma melhor escolaridade, de tipologia de família nuclear e acompanhavam com maior assiduidade a vida escolar das crianças. Por outro lado, as famílias cujos filhos tinham baixo desempenho eram, em sua maioria, de tipologia extensa/ampliada, com baixa escolaridade, desempregada e acompanhavam pouco as atividades desempenhadas na escola. $\mathrm{O}$ estudo, portanto, revela a família como um elemento central no rendimento escolar de seus filhos, além da influência da configuração socioeconômica nas ações desempenhadas ${ }^{6}$.

Em relação ao coordenador pedagógico, no referido trabalho este não aparece como sujeito central da pesquisa, mas somente como um dos entrevistados. Em um dos trechos da dissertação, é mencionado o papel de formador desse coordenador, quando se questiona a formação continuada dos professores e são apontadas, como parte desse processo, as reuniões quinzenais promovidas no espaço da escola junto ao corpo docente. Além dessa função, o coordenador aparece como responsável pela organização de informações referentes ao rendimento dos alunos. Ao final de cada ano letivo, ele elabora um documento com a estatística oficial da escola, referente a dados como: percentuais de transferência, aprovação, reprovação, evasão escolar e distorção idade-série. Chama-se a atenção para o fato de que o coordenador entrevistado atua na referida instituição por 20 horas semanais, exercendo o magistério em outra escola nas demais 20 horas. Um dado interessante apresentado pela pesquisadora é uma tabela com a distribuição percentual das respostas dos responsáveis entrevistados sobre quais os elementos mais importantes para que uma escola seja boa (respostas espontâneas). Enquanto qualidades como "ter bons professores" e "ter boa estrutura física" aparecem na maioria das respostas $(21 \%$ e $13 \%$ respectivamente), a característica "ter boa direção/coordenação" aparece em somente $6 \%$ das respostas.

O quinto trabalho analisado é a dissertação de mestrado (em Educação) de Ferreira (2009), intitulada "É possível promover o sucesso escolar? um estudo a partir do pensamento das educadoras das séries iniciais". A pesquisadora buscou analisar e compreender os pressupostos teóricos, crenças e valores dos educadores de séries iniciais com o intuito de identificar elementos que promovam o sucesso escolar dos alunos. Para tanto, realizou um estudo de caso com realização de entrevistas com professoras e coordenadoras pedagógicas de três escolas de ensino fundamental da cidade de São Paulo/SP. Os dados da pesquisa revelam que há uma deficiência teórica por parte dos professores, havendo a necessidade de uma aproximação entre os conhecimentos produzidos na academia e as práticas educativas. Além desse aspecto, a autora aponta que é preciso um melhor diálogo no interior da escola a respeito das responsabilidades pela educação das crianças, com uma parceria entre escola e família e uma educação em valores, voltada ao convívio com a diversidade. Também é apontado como necessário o investimento em formação continuada dos professores, o que envolve o trabalho do coordenador pedagógico.

Em relação à função desse profissional, a autora faz uma digressão histórica e destaca, na escola tecnicista presente no Brasil a partir da instalação da Ditadura Civil-Militar, o trabalho fiscalizador desempenhado por esse agente. Naquele momento histórico, os chamados técnicos da educação exerciam "[...] um papel de controle e organização dos processos escolares, exigindo de seus docentes o cumprimento de planos entregues para serem executados." (FERREIRA, 2009, p. 37). Nesse cenário, o professor era um mero executor de propostas. Ainda analisando o papel do coordenador, a autora dá destaque a este como um dos agentes responsáveis pela formação continuada dos professores e defende que essa formação precisa levar em consideração as especificidades da instituição:

Quando destacamos o trabalho $d a$ formação continuada, não estamos nos referindo a um processo qualquer, mas a uma ação que considere o contexto real da escola e suas condições reais de trabalho, que se proponha a desenvolver uma nova consciência junto a educadores, atores criativos, com ação intelectual e sensivel que sabem refletir sobre seus fazeres. (FERREIRA, 2009, p. 47-48).

Diferentemente dos trabalhos supracitados, essa autora dedica um tópico de sua dissertação para discutir especificamente sobre o papel do 
coordenador pedagógico. Ela coloca-o como um colaborador que atua na formação do professor, possibilitando a este a reflexão sobre sua prática. Cabe ao coordenador desenvolver indagações que incentivem o professor a pesquisar sobre seu fazer cotidiano, relacionando a teoria ao seu compromisso social. A autora avalia, nas instituições analisadas, as reuniões coletivas como importantes para esse momento de reflexões e trocas entre professores e coordenador, porém destaca que muitas vezes esse momento é pouco aproveitado, colocando em pauta assuntos aleatórios e pouco frutíferos quanto à prática pedagógica.

Analisando as falas das coordenadoras entrevistadas, a pesquisadora observa que muitas vezes o papel da coordenação se estrutura na escola, no próprio exercício da profissão, e nem sempre esse profissional consegue exercer plenamente a sua função. Trazendo contribuições de Christov (2003 apud FERREIRA, 2009), a autora aponta algumas razões para que o exercício da coordenação não se dê de forma plena: 1) a relação (de poder) que há entre direção e coordenação; 2) relação do sistema de ensino com a coordenação pedagógica, que muitas vezes faz com que esse agente precise comparecer a eventos promovidos pelos órgãos centrais em momentos em que deveriam estar com os professores; 3) o entendimento, por parte dos professores, sobre a função do coordenador: ora como alguém que vá apresentar ideias para as aulas, ora para interceder junto aos pais para defender os docentes e/ou exigir que eduquem bem seus filhos.

Diante desse cenário, é trazido um trecho interessante do que defende Christov (2003 apud FERREIRA, 2009, p. 164):

Por mais autoritária que possa se apresentar à direção, a supervisão e até mesmo o corpo docente, o coordenador consciente de sua importância como formador e consciente de que o espaço escolar não está isento de confrontos perpassados por relações de poder conta com a possibilidade de se colocar como sujeito que cria situações e reverte fatores de impedimento, superando a condição de vítima de um contexto opressor.

Diante dessa discussão, a autora busca colocar o coordenador como um autor de mudanças, sendo necessário que ele não somente fomente a reflexão dos professores, mas também ele mesmo pense sobre sua prática.

A tese de doutorado (em Educação) de Oliveira (2011), intitulada "A relação entre a família e a creche pública no cuidado e na educação das crianças", apresenta como objetivo analisar como as relações entre as famílias e as creches públicas são construídas no cotidiano. Para tanto, a autora pesquisou duas Unidades Municipais de Educação Infantil (UMEIs) da cidade de Belo Horizonte/MG, buscando analisar os espaços criados pelas instituições para se relacionarem com as famílias das crianças, além de desvelar as expectativas das famílias e educadoras infantis sobre a função da creche. O referencial adotado é Pierre Bourdieu e Remi Lenoir para discutir sobre família e Estado e Norbert Elias para entender as relações entre essas duas instituições. A metodologia envolveu observações, entrevistas semiestruturadas e questionários.

De sua análise, a autora depreendeu que ambas as instituições desenvolvem ações para favorecer a participação das famílias, como acompanhamento, por parte destas, de atividades desenvolvidas pelas crianças, além da participação em eventos, como festas, reuniões e atividades extraescolares.

Em relação ao papel do coordenador pedagógico, a pesquisadora dá destaque a ele, colocando-o como um mediador dos conflitos e tensões nessa relação entre a creche e a família. Em uma das instituições observadas, a autora identificou que o espaço da coordenação era reservado a orientar as famílias sobre os cuidados com seus filhos, tanto em relação à higiene, quanto ao cumprimento das normas da creche, além de ouvir as queixas das famílias em relação à instituição ou o relato de episódios pessoais ligados ou não às crianças. Após ouvir as famílias, a coordenadora, junto com a vice-diretora, reunia-se com as educadoras para refletir sobre a situação colocada. Do mesmo modo, a coordenação ouvia as queixas das educadoras em relação às famílias e estabelecia momentos para orientá-las de acordo com o que era observado, sublinhando a necessidade de observância das normas da instituição.

Outro aspecto da função desse profissional nas instituições observadas é a formação das educadoras, geralmente com ênfase no cuidar. A harmonia entre direção e coordenação, por sua vez, é apontada pela autora como favorecedora de um ambiente de parceria com as famílias, em uma das instituições pesquisadas. Nessas instituições, eram criados espaços de encontros cotidianos, na saída e na entrada das crianças, projetos pedagógicos que envolviam as famílias, seminários temáticos e envolvimento dos responsáveis na elaboração do Projeto Político-Pedagógico (PPP).

O sétimo trabalho analisado é a tese de doutorado (em Educação) de Negri (2012), 
intitulada "A responsabilidade social no mercado escolar: uma análise sociológica das demandas parentais em suas relações com a oferta educativa". O objetivo da autora foi explorar o fenômeno da responsabilidade social escolar, ou seja, as propostas e práticas pedagógicas desenvolvidas por estabelecimentos privados de ensino visando às demandas atuais da sociedade. Para tanto, foram levantadas escolas da rede privada localizadas em áreas nobres de Belo Horizonte/MG.

A partir da análise de suas propostas pedagógicas, a pesquisadora classificou os estabelecimentos em três grupos, de acordo com as diferentes abordagens educativas de responsabilidade social. Posteriormente, selecionou uma escola de cada grupo e realizou um estudo de caso, buscando investigar de que forma as propostas se articulam com as demandas parentais. A metodologia envolveu entrevistas com coordenadores pedagógicos e pais, observações das ações sociais e análise de documentos (das instituições, publicações na mídia e dados estatísticos). O referencial envolveu os estudos de Bourdieu e abordagens contemporâneas sobre o objeto. O estudo revelou a intensificação de paradoxos na relação família-escola. Por um lado, os pais mostram-se confusos a respeito do que esperam da escola, por outro, os estabelecimentos de ensino desenvolvem propostas pedagógicas mais relacionadas a estratégias de marketing do que ao desenvolvimento de práticas de cidadania.

Embora a discussão sobre o papel do coordenador pedagógico não seja central no referido trabalho, o histórico de uma das instituições analisadas revela a importância desse profissional. Dez anos após a fundação de um colégio que buscava implementar um projeto pedagógico inovador e democrático, conflitos entre a coordenação e a direção culminaram na saída das coordenadoras e no fechamento da escola. Isso porque, após o desligamento da coordenação, muitos pais retiraram seus filhos da instituição com receio de que esta não teria mais "sustentação pedagógica". Ao longo do trabalho, fica evidente a relevância do papel da coordenação pedagógica para a elaboração e consolidação das propostas das instituições pesquisadas.

Por fim, na tese de doutorado (em Educação) de Moreno (2012), intitulada “A relação professor-escola-família na educação da criança de 4 a 6 anos: estudo de caso em duas instituições de ensino da cidade de Londrina", a autora buscou analisar esse objeto investigando como professores, famílias e equipe técnica (direção e coordenação) concebem a relação entre si e verificando as estratégias adotadas pela escola para incentivar a participação das famílias e dos professores na educação das crianças. As instituições selecionadas para o estudo de caso foram duas, uma privada e uma pública, localizadas na região central da cidade de Londrina/PR. A metodologia adotada envolveu aplicação de questionários, análise documental, observação e diários de campo.

Os dados analisados revelaram a importância de estudos e discussões sobre a diversidade de arranjos familiares na escola e do contato direto de professores e equipe técnica com as famílias, diversificando os instrumentos de comunicação e as estratégias de trabalho junto a estas, além da importância da lição de casa como um meio de favorecer essa aproximação. Também foram revelados encontros e desencontros de ideias entre os agentes pesquisados. Em ambas as instituições, a participação da família na elaboração do Projeto Político Pedagógico (PPP) revelou-se baixa ou ausente.

O papel da coordenação pedagógica é pouco abordado no trabalho. Menciona-se a sua atuação na recepção dos pais (juntamente com direção e uma professora auxiliar) no momento da entrada ou saída das crianças, quando então os recados são anotados para posteriormente serem transmitidos à professora. Trata-se, portanto, de uma função de mediação, pois, em vez de os responsáveis se dirigirem diretamente à professora, têm na coordenação essa possibilidade de ver suas demandas atendidas e encaminhadas. Além dessa função de ouvir as solicitações, a coordenação (e direção) orienta em relação ao auxílio nas tarefas por parte das famílias, destacando a importância desse acompanhamento para o desenvolvimento das crianças. Também aparece como função da coordenação apresentar a instituições aos pais, seja em relação ao currículo, seja a estrutura física.

Como se pode observar nos trabalhos analisados, o papel do coordenador pedagógico é multifacetado. Ora ele aparece como um formador dos professores, ora como um mediador de conflitos, ora como um ouvinte/orientador das famílias. Também nota-se a importância desse agente no planejamento e implementação da proposta pedagógica da escola e também como um representante da instituição, que apresenta esta à família, no que se refere à filosofia adotada, currículo, normas e estrutura física. São colocadas, ainda, sobre o coordenador, expectativas em relação ao auxílio na elaboração das aulas, organização das reuniões e demais atividades que integrem a família à escola, além da composição dos dados estatísticos sobre o rendimento dos alunos.

Coloca-se em questão, diante dessa variedade de funções que se colocam ao 
coordenador pedagógico, a necessidade de se estabelecer uma noção clara dos limites de suas atribuições. Levanta-se a hipótese de que esse profissional, ao assumir inúmeras responsabilidades, atuando em diversas frentes, acaba por não dedicar tempo suficiente para o que seria o seu papel central: a formação continuada dos professores. Dados os limites deste artigo, fica como sugestão para próximos trabalhos explorar essa problemática.

\section{Da relevância social e acadêmica do objeto de estudo}

Em pesquisa, é necessário estar atento e aberto ao inesperado. A ausência de dado também é um dado. Essencialmente, o levantamento aqui realizado contribui para esse entendimento, ao se observar a escassez de trabalhos com o objeto enfocado - a relação escola-família e o papel do coordenador pedagógico.

Quando se propôs este estudo, a expectativa era de que, como as pesquisas sobre famílias e escolas estão cada vez mais presentes, e considerando o papel do coordenador pedagógico como um mediador importante na relação entre essas duas instituições, haveria um acervo considerável de artigos, dissertações e teses com essa temática. No entanto, observou-se não somente que havia poucos trabalhos sobre esse tema, mas também que, desses poucos, nenhum traz como elemento central a discussão sobre o papel do coordenador.

A função desse agente tem passado por mudanças significativas nas últimas décadas; no entanto é surpreendente que essa questão não tenha recebido a devida atenção por parte dos pesquisadores, ao menos no que se refere à relação escola-família. Sendo assim, ressalta-se a relevância acadêmica de estudos com esse objeto: a quase ausência de pesquisas com esse tema.

Em relação à relevância social, observa-se a necessidade de se entender esse coordenador que aí está, objetivando identificar suas dificuldades e os avanços que têm sido alcançados, especialmente no que se refere ao favorecimento da parceria entre a escola e a família, duas instituições que, como defende Orsolon (2012) têm se reestruturado e cuja relação nem sempre é harmoniosa, inclusive pelo fato da intensificação da confusão de papéis.

Essa confusão de papéis também acaba refletindo na função do coordenador pedagógico, que tem visto suas atribuições aumentarem, o que muitas vezes acaba configurando seu fazer profissional de acordo com as demandas que vão aparecendo, e não a partir de uma consciência real de seu papel. Daí a necessidade de essa questão estar em pauta na academia, e ser divulgada nos cursos de formação de professores e nas escolas, ou seja, é urgente que as dificuldades enfrentadas por esse profissional se tornem públicas, para que se busquem formas de superá-las. Ao se reivindicar essa aproximação da universidade às demandas da sociedade, não se está reduzindo a pesquisa a um caráter pragmático, mas se está questionando justamente até que ponto o que se tem produzido tem se revestido dessa relevância social e contribuído para as mudanças necessárias.

\section{Considerações Finais}

A partir das discussões desenvolvidas ao longo do artigo, retoma-se a problematização levantada buscando sintetizar o que o trabalho possibilitou revelar.

1) Qual a incidência de investigações que tratam da relação escola-família, em especial no que se refere à função desempenhada pelo coordenador pedagógico?

Dos 8 trabalhos levantados, somente 2 dão um enfoque maior ao papel do coordenador pedagógico, porém nenhum deles tem este como objeto. Em sua maioria, os coordenadores aparecem somente como sujeitos entrevistados, visando a apreender a concepção destes a respeito da relação escola-família.

2) Quais as abordagens teóricas e metodologias empregadas nesses estudos?

As abordagens teóricas, embora nem sempre apareçam de forma clara, são diversas e passam por contribuições de Bourdieu, Norbert Elias, Piaget, Ariès, Foucault entre outros. Quanto à metodologia, a maioria dos pesquisadores empregou entrevistas e observação, porém também foram aplicados questionários e análise de documentos.

3) Quais grupos sociais têm sido enfocados?

Os grupos pesquisados também são heterogêneos. Os pesquisadores tiveram como locus escolas particulares e públicas, de educação infantil e ensino fundamental; e como sujeitos famílias de camadas populares e médias, professores, diretores e coordenadores pedagógicos.

4) Qual a relevância atribuída ao coordenador pedagógico nesse processo?

O papel do coordenador pedagógico é multifacetado. Ora ele aparece como um formador dos professores, ora como um mediador de conflitos, ora como um ouvinte/orientador das famílias. Também notase a importância desse agente no planejamento e implementação da proposta pedagógica da 
escola e também como um representante da instituição, que apresenta esta à família, no que se refere à filosofia adotada, currículo, normas e estrutura física. São colocadas, ainda, sobre o coordenador, expectativas em relação ao auxílio na elaboração das aulas, organização das reuniões e demais atividades que integrem a família à escola, além da composição dos dados estatísticos sobre o rendimento dos alunos.

Essencialmente, no entanto, suas funções são de formador dos professores e mediador na relação entre a escola e as famílias.

Esta pesquisa revelou que, a despeito da pertinência do objeto, são quase ausentes os trabalhos que enfocam o coordenador pedagógico frente à relação escola-família. Espera-se que esse dado fomente estudos posteriores a respeito da temática, tendo em vista a importância do coordenador pedagógico como um agente mediador no ambiente escolar.

A respeito de nossa atuação profissional, nota-se que há certa indefinição sobre o que se espera do coordenador. Por vezes, a diversidade e o volume considerável de tarefas a ele atribuídas acaba por dificultar que ele se aprofunde e se dedique a mudanças significativas na escola, pois as demandas imediatas lhe tomam um tempo considerável. Este trabalho, portanto, contribui para que se reflita sobre essa questão, buscando-se uma definição mais clara sobre o papel desse profissional.

\section{Notas}

1 Participamos do Grupo de Estudos e Pesquisas em Antropologia e Sociologia da Educação (GEPASE) da Universidade Federal de Mato Grosso do Sul (UFMS) e desde o ano de 2008 nos dedicamos a estudos e pesquisas a partir do referencial bourdieusiano.

2 Combinaram-se as seguintes palavras-chave: "família", "escola" e "coordenador pedagógico"; "famílias", "escolas" e "coordenador pedagógico"; "família", "escola" e "coordenação pedagógica"; "família" e "coordenação pedagógica".

3 Realizando uma busca rápida nas mesmas bases de dados, utilizando somente as palavras-chave "família" e "escola", obteve-se um total de 2624 trabalhos na BDTD e 338 na Scielo. Foge aos limites deste estudo verificar o conteúdo desses trabalhos, pois o grande volume torna essa leitura inviável. É possível que desse universo significativo, haja produções que contemplem a função do coordenador pedagógico, no entanto não se pode, neste momento, realizar essa busca.
É por esse motivo que se reitera a necessidade desses softwares dos bancos de dados serem aperfeiçoados, estendendo a busca por palavraschave aos textos na íntegra, o que possibilitaria ao pesquisador identificar com maior facilidade, tendo em vista que muitas vezes os resumos não revelam o essencial das pesquisas.

$4 \mathrm{O}$ referido estudo enfoca o sucesso escolar nas camadas populares. Foi realizada uma busca nos mesmos bancos de dados - BDTD e Scielo.

5 Conforme dados obtidos no site da CAPES, atualmente, a região Norte possui 256 cursos de pós-graduação stricto sensu, a região Nordeste possui 1033, a região Centro-Oeste possui 434, a região Sudeste, 2763 e a região Sul, 1185 (CAPES, 2014)

6 Embora esta não seja uma discussão central neste artigo, é interessante trazer algumas questões que foram levantadas em outro trabalho produzido por nós recentemente para uma disciplina de doutorado em educação, intitulado "A produção do sucesso escolar nas camadas populares: estado do conhecimento e relevância do objeto". No referido artigo, observou-se que mesmo quando os trabalhos acadêmicos enfocavam uma mesma classe social - nesse caso, as camadas populares -, o entendimento de "sucesso escolar" era heterogêneo, o que revela que, dentro de uma mesma classe social, há uma variedade de configurações que acaba por influenciar o que se entende por trajetórias escolares de êxito. Passa-se a entender que não há um conceito único. O que definirá o que se pode conceber como "sucesso" são as singularidades dos grupos pesquisados, assim como o grau de esforço empregado pelo agente e sua família ao longo dessas trajetórias. No caso enfocado por Moraes (2008), essa questão se torna também evidente, dado que mesmo pesquisando alunos de uma mesma instituição escolar, observa-se uma heterogeneidade na configuração e nas ações de suas famílias, as quais têm influência direta no rendimento escolar. (SILVA, 2014).

\section{Referências}

CAPES. Coordenação de Aperfeiçoamento de Pessoal de Nível Superior. Cursos recomendados/reconhecidos. Disponível em: <http://www.capes.gov.br/cursos-recomendados> Acesso em: 19 jul. 2014.

DAYRELL, J. et. al. Apresentação. In: DAYRELL J. et. al (Org.). Família, escola e juventude. 
Olhares cruzados Brasil-Portugal. Belo Horizonte: Editora UFMG, 2012, p. 9-19.

FACHINI, M. A. A. Coordenação pedagógica. Fundamentos teóricos e práticos da coordenação pedagógica. Campo Grande: UCDB/Portal Educação, 2013.

FERNANDES, J. A relação escola e família no Ensino Fundamental da rede privada na perspectiva do Coordenador Pedagógico. Dissertação (Mestrado). São Paulo: PUC-SP, 2006.

FERREIRA, N. S. A. As pesquisas denominadas "estado da arte". Educação \& Sociedade, Campinas, ano 23, n. 79, p. 257-272, ago. 2002. Disponível em: <http://www.scielo.br/pdf/es/v23n79/10857.pdf> Acesso em 19 jul. 2014.

FERREIRA, S. G. P. É possível promover o sucesso escolar? um estudo a partir do pensamento das educadoras das séries iniciais. Dissertação (Mestrado). São Paulo: USP, 2009.

GARCIA, H. H. G. O. Família e escola na educação infantil: um estudo sobre reuniões de pais. Dissertação (Mestrado). São Paulo: USP, 2005.

MORAES, R. C. A. F. Contribuições de famílias para o rendimento escolar de alunos de 1 a 4 séries do ensino fundamental: olhares das responsáveis e das professoras. Dissertação (Mestrado). Salvador: UCSAL, 2008.
MORENO, G. L. A relação professor-escolafamília na educação da criança de 4 a 6 anos: estudo de caso em duas instituições de ensino da cidade de Londrina. Tese (Doutorado). São Paulo: USP, 2012.

NEGRI, S. R. A responsabilidade social no mercado escolar: uma análise sociológica das demandas parentais em suas relações com a oferta educativa. Tese (Doutorado). Belo Horizonte: UFMG, 2012.

OLIVEIRA, M. G. A relação entre a família e a creche pública no cuidado e na educação das crianças. Tese (Doutorado). Campinas: UNICAMP, 2011.

ORSOLON, L. A. M. Trabalhar com as famílias: uma das tarefas da coordenação. In: PLACCO, V. M. N. S.; ALMEIDA, L. R. (Orgs.). O coordenador pedagógico e o cotidiano da escola. 9 ed. São Paulo: Edições Loyola, 2012, p. 177-183.

SILVA, M. M. Família na escola: olhando fotografias, lendo textos culturais. Dissertação (Mestrado). São Leopoldo: UNISINOS, 2007.

ZAGO, N. Processos de escolarização nos meios populares: as contradições da obrigatoriedade escolar. In: NOGUEIRA, M. A.; ROMANELLI, G.; ZAGO, N. (Org.). Família e escola: trajetórias de escolarização em camadas médias e populares. 5. ed. Petrópolis: Vozes, 2008, p. 17-43.

\section{Sobre as autoras:}

Alice Felisberto da Silva: Doutoranda em Educação do PPGEdu/UFMS e aluna de especialização em Coordenação Pedagógica (UCDB). Possui graduação em Pedagogia (2006-UFMS), especialização em Planejamento e Tutoria em EAD (2009-UFMS) e Mestrado em Educação (2010-UFMS). Atua como coordenadora pedagógica.

Maria Ângela Bariani de Arruda Fachini: Mestre em Educação (UFMS), Especialista em Fundamentos Filosóficos da Educação (UFMS), graduada em Pedagogia (FUCMAT). Professora Orientadora de Pósgraduação a distância em Gestão Escolar da UCDB (lato sensu).

Artigo recebido em novembro de 2014.

Artigo aprovado em abril de 2015. 